\title{
Organizational and methodological aspects for contemporary health and safety management system
}

\author{
Evgeny Sugak ${ }^{1, *}$ \\ ${ }^{1}$ Moscow State University of Civil Engineering, Yaroslavskoe shosse, 26, Moscow, 129337, Russia
}

\begin{abstract}
Industrial injuries and work-related disorders considerable lowering we are facing in developed countries may be due to switching to a new health and safety management system entitled "Occupational Safety and Health Management System". The Russian Federation has prepared certain regulatory documents prescribing some suggestions regarding implementing the contemporary system for industrial injuries prevention based upon the methods for professional risks management. However, despite the efforts made by the Russian Government, reformation of the health and safety management system at various companies is being performed rather slowly that may be as well owing to poor competence of managers and specialists regarding contemporary labor safety model content, methodical and organizational novations in the sphere of occupational safety and health management.. The article refers to a number of principal issues distinguishing the new health and safety management system from conventional approach.
\end{abstract}

\section{Introduction}

Over the recent decades we are facing favorable changes in the level of industrial injuries and work-related disorders in developed countries. Positive tendencies in labor losses reducing may be due to development and reduction to practice a new health and safety model based on which a contemporary management system was built entitled "Occupational Safety and Health Management System (OSHMS)" [1,2]. Switching to new ways of economic management resulted from resources depletion offered by traditional methods for health and safety management that in day-to-day realities of postindustrial economy were performing poorly with regard to accidents and work-related disorders reducing, failed to provide proper efficiency concerning manufacturing costs reducing in the course of labor force cost increasing.

Occupational Safety and Health Management Systems after being reformed happened to show their advantages fast enough. For instance, at German companies during 1968-1983 fatal outcomes at work reduced almost thrice; other incidents and diseases quantity and severity lowered subsequently [3]. According to estimates made by the International Labour Organization (ILO), developed countries have almost settled the matter of how to

*Corresponding author: SugakEB@mgsu.ru 
protect a man from injuries; there are only a few positions having unacceptable hazard and harm level. Due to the fact that in European countries health care costs in case of treatment providing for work-related disorders under current conditions go far beyond the expenses for an injured rehabilitation after some industrial injury, health and safety activity primarily focuses upon the programs for employees health preservation. This is why the main line of activities regarding health and safety protection as for today is working conditions improvement, working places comfort raising [4].

However, the main effect of reforms performing was a bit different. The measures for labor safety improving on the basis of fixed assets upgrading, manufacturing facilities and devices upgrading, companies infrastructure optimization encouraged the improve ment of manufactured products and services quality, labor efficiency increasing, had a positive effect on employees engagement, positively affected companies economic results and their competitive ability. According to the data displayed in annual polls of the employers from the European Union, most of them admit that improving working places safety and comfort is their overriding priority, ensuring reliable and effective basis for the company's sustainable and long-term development [4].

One of recent study having lasted for two years in 300 companies in 16 European countries found out that return on investments made to health and safety on the average more than twice increases such investments amount. It means that each Euro spent by a company for preventive measures to lower accidents and work-related diseases strengthens such company's economic capacity by 2.2 Euro. And for companies having certain troubles in the sphere of health and safety or for companies having limited experience in this sphere the aforementioned positive effect turned out to be even greater. The collaborative study was being performed with the support of the International Association for Social Security, German Society for Compulsory Insurance and German Society for Professional Insurance of Those Employed in the Energy Industry [5].

\section{Methods}

The Russian Federation since the beginning of the 90s has been implementing certain provisions of the Occupational Safety and Health System Model. For instance, federal acts "On Occupational Safety and Health in the Russian Federation" and "On Compulsory Social Insurance against Accidents and Work-Related Disorders" have been adopted, government-sanctioned programs for working places assessment and special evaluation as to labour conditions are being performed with varied success. About 10 years ago National Standard GOST 12.0.230-2007 "Health and Safety Management Systems. General Requirements" was introduced, and the text thereof keeps to the regulatory document prepared by the International Labour Organization (ILO OSH - 2001). In October 2011 the Russian Government held a special meeting dedicated to the challenges regarding health and safety management system modernization where a respective directive was made. Soon GOST P 54934 - 2012 "Health Protection and Labor Safety Management Systems" was developed and adopted, and the contents thereof is identical to International Standard OHSAS 18001:2007. National and International Standards in Health and Safety suggest a systematic approach to changing the management methods and arrangements and prescribe a whole range of consequential procedures to undertake [6-9].

In consequence of cooperation shown by public authorities and manufacturing companies management during the recent 15 years the Russian statistical agencies are recording constant lowering of registered accidents at working places total number, and this shall be deemed a major asset. Fatal outcome industrial injuries are lowering as well, however much more poorly. However, collateral data evidence that it is too soon to claim any strong favorable results in labor conditions improvement. For instance, on the 
background of accidents frequency rate lowering (determines the number of incidents per a calendar year for 1,000 employees) injuries severity rate has risen, i.e. disability days number per an industrial injury has grown by $33 \%$ from 34.2 days to 45.6 days [10]. Thus, we are facing a rather contradictory tendency: in the course of incidents number reducing attending to working places safety increasing an injured damage degree is rising, that just the other way round points out the situation with labor conditions deterioration.

Harmful labor conditions lead to a great number of work-related disorders, and the number of those having discovered they are suffering from work-related disorders is annually increasing by $7-8$ thousand people. The share of employees working under harmful labor conditions is still increasing. So, as for the beginning of 2011 almost every third Russian employee had to work under harmful labor conditions.

Upon expert findings of the All-Union Research Institute of Health and Safety and Labor Economics of the Ministry of Labor of the Russian Federation total losses due to un satisfactory employees health and safety and labor conditions in 2011 made 1.94 trillion RUR per annum or $4.3 \%$ of the GDP. Thereby, working time fund losses due to unfavorable labor conditions according to estimations amounted to 1.48 trillion RUR (76\% of the total losses), payments made by the Retirement Fund of the Russian Federation regarding early pensions for working under harmful labor conditions fixed to be equal to 300 billion RUR (15\% of the total loss), payments made by the Social Security Fund as insurance benefits due to accidents and work-related disorders amounted to 159 billion RUR ( $8 \%$ of the total loss) [11]. Thus, most losses are incurred by companies due to labor losses owing to general diseases, so-called diseases caused by manufacturing process resulting from unfavorable labor conditions.

Ambiguous account of the situation with industrial injuries is poorly correlated to positive changes that took place and are still happening in working places technical and technological arrangements, in companies infrastructure quality improvement. In the context of new economy advanced capabilities have appeared to renew machine-tool fleet, to procure new equipment and hand-guided tools, to implement modern technologies. The country has launched quite a few new innovative manufacturing methods having improved technical and economic and environmental performances that have inter alia advanced characteristics in health and safety and manufacturing productivity.

Fixed assets upgrading shall have positive results and it is quite natural that they may be observed in the industrial injuries statistics. However, when working at the equipment similar to that used in developed countries, applying identical technologies and tools, Russian employees in this case take certain risks to have some industrial injury or workrelated disorder far more frequently than their foreign colleagues. So, according to statistical data, in European countries fatal outcomes are fixed 3-9 times more seldom than in Russia though working places material and technical outfit and technological processes in our country are rather close and differ not so strikingly. Another alarming fact is that in Russia from every 22 registered accidents one injury leads to fatal outcome, and in European countries fatal incidents are fixed on the average out of 500-2000 registered incidents [10].

Success in any aspect of industrial activity, including regarding improvement of the situation with industrial injuries shall be determined by the development level of the three components of each working process and their effective coordination among themselves (Figure 1). The three sectors of a large circle reflect the state of working places technical and technological arrangements, personnel competence level and quality of manufacturing management and arranging. To create safe environment we shall take into consideration all the three components of the labor process though each of them has different impact on the situation with industrial injuries and work-related disorders. An optimum option shall 
provide a harmonious composition of objective and subjective safety factors characterizing comfortable labor conditions and responsible and professionally competent personnel.

In the judgement of the Russian Government the most urgent challenge as for today is the large-scale assignment in connection with health and safety management system upgrading that had a few changes compared to that in the USSR. There was an assumption that in the current context of market economy it does not ensure injuries and disorders reducing, fails to encourage employers to improve labor conditions, is not focused upon preventing dangerous and harmful manufacturing factors appearing but upon clearing the consequences of industrial injuries and work-related disorders, upon compensations payment to personal who have to work under harmful conditions. Thus, the Russian Government has set up a task to develop a new health and safety management system that instead of responding methods and procedures to any manufacturing incidents shall perform preventive activity in connection with professional risks discovering, distinguishing, estimating and eliminating or lowering [11].

However, in practice despite certain basic regulatory documents the health and safety management system at companies is being reformed rather slowly, the practices typical for conventional health and safety model are still dominating based not upon establishing a safe manufacturing environment but upon supervision and control over the personnel's fulfillment of labor protection requirements. National standards provisions implementation strikes a number of hindrances, and one of them is managers and specialists poor competence regarding contemporary labor safety model content, its essence and differences from conventional approach, health and safety activity methodological grounds, structural and functional novations within the company, economic efficiency of measures to improve health and safety and regarding any other urgent matters.

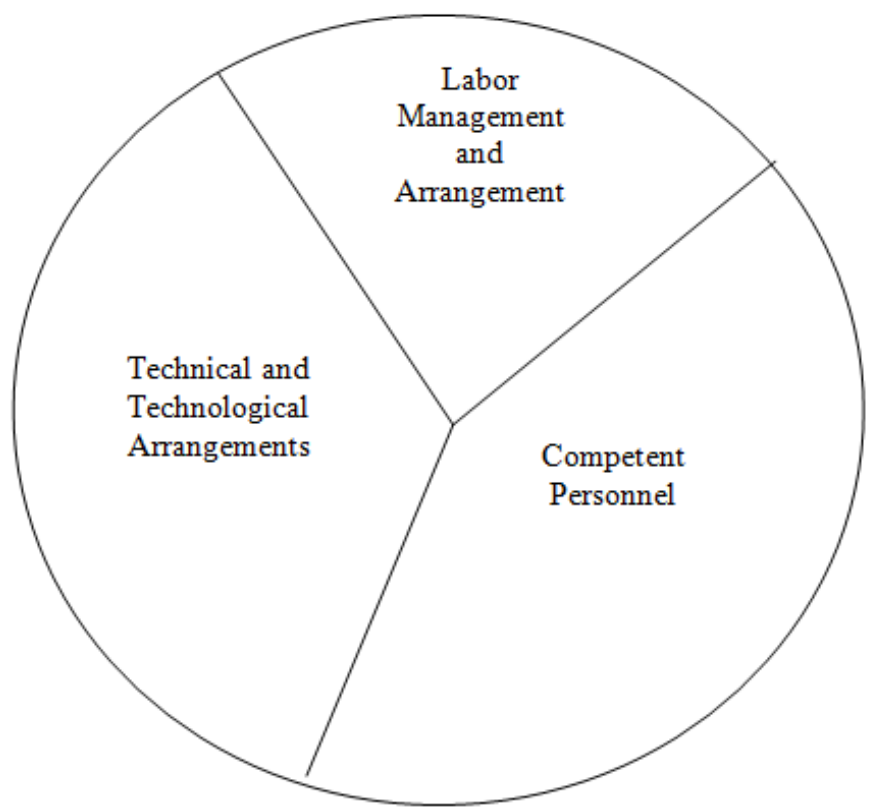

Fig.1. Manufacturing Process Components. 


\section{Results}

Contents of contemporary view regarding health and safety protection and its difference from conventional practices are as follows:

I. Accidents arising objective nature. One of principal peculiarities of the reformed model is changing the idea of accidents arising nature. In the context of conventional approach manufacturing incidents arising is attributed to subjective reasons happening due to employee's breaching labor protection requirements. On the manufacturing worker's level such version may seem valid enough however to operations manager it provides no opportunity to effectively perform preventive measures, to make estimations, to assess and manage professional risks working place [12]. When such hazards and harmfulness appear, they inflict damages of a certain severity to an employee, including labor capacity losing. The more hazards and harmfulness there appear during the manufacturing process, as a rule, the more accidents and work-related disorders there arise.

Hazardous and harmful factors may rest in two various states, in explicit form and in hidden or implicit form. Explicit form includes any and all hazards and harmful conditions that could be observed, caused respective damage to an employee's health, in the incident investigation process negative factors are documented and legalized in such a way. The degree of an employee's injury, being slight, moderately severe or severe, shall not be taken into consideration in the course of registering this or that hazard or harmful condition. It is the fact of manufacturing hazards and harmful conditions that matters, but not the negative effect measure from its impact.

Any manufacturing hazards and harmful conditions found in the labor process but not appearing yet, having no external effect on human body and respectively causing no injury to him, refer to hazardous and harmful factors being in hidden, implicit form. They represent particular threats to labor safety due to the fact that firstly there are a lot more of them than of the hazards having appeared and damaged an employee's health, secondly, they are in unperceivable implicit state and they shall be discovered by some complicated means, and thirdly, their potential impact on personnel may cause far more unexpected and unpredictable consequences [12].

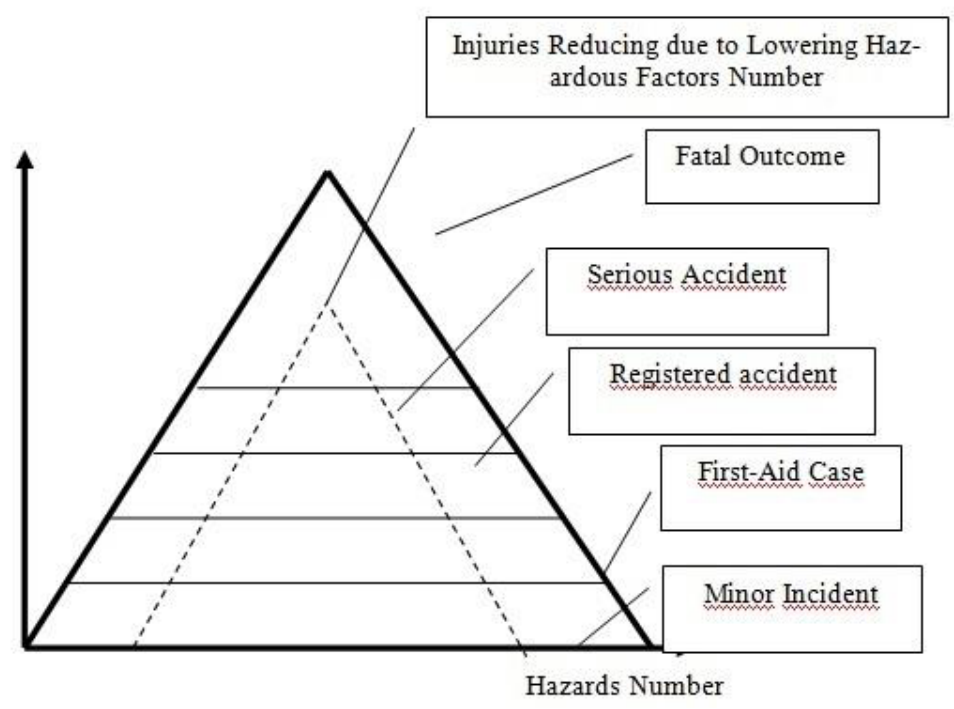

Fig. 2. Injuries Pyramid. 
Manufacturing hazards and harmful conditions appearing in explicit and implicit state and any health damages caused by them are displayed in "the Injuries Pyramid by G. W. Heinrich" [13]. Such pyramid's layers reflect the severity degree of manufacturing environment adverse impact (Figure 2):

1. Minor Incident happens when a hazard has appeared but caused no external injury for an employee.

2. First-Aid Case happens when a hazard has appeared and caused an injury that had no impact on employee's working capacity but required first-aid treatment.

3. Registered accident happens when a hazard has appeared and caused an injury to an employee that resulted in his work incapacity. Such incident is treated as an accident and shall be registered in a proper way.

4. Serious Accident happens when a hazard has appeared and caused severe injury being a group incident or a single incident resulting in an employee becoming a disabled person.

5. Fatal Outcome happens when a hazard has appeared and caused fatal injuries.

G.W. Heinrich has stated that there is a certain stable mathematical dependence of the number of hazardous manufacturing factors and severity degree of their appearing. Namely, among 29-30 accidents having less serious consequences and work incapacity there is one severe injury or work-related death, and 300-330 minor incidents that may pass by almost unobserved [13].

Discovered numerical dependence between accident's severity degree and the number of hazardous manufacturing factors is firstly another confirmation of objective nature of industrial injury appearing and secondly analytically estimated correlation enables to formulate the principal content and essence of health and safety methods. Having analyzed the Injuries Pyramid we discovered that concentration of specialists' efforts in labor safety to implement measures lowering, for instance, the number of registered accidents or of fatal incidents fail to provide any considerable effect since they do not affect events particular reasons. Only reducing the bottom of the Injuries Pyramid, i.e. reducing the number of hazards and harmful conditions, enables to reduce the number of incidents respectively for each injuries severity degree.

Acknowledging the objective nature of accidents and work-related disorders appearing implies that preventive measures shall also have objective content aimed to lower the level of manufacturing hazards and harmful conditions. Namely, performing the works to change operational procedures, to use less hazardous and safe materials and devices, to apply effective safety systems and devices that taken together shall enable to create reasonably safe manufacturing environment. We must point out that an objective safety factor for manufacturing process shall be formed solely through technical and organizational methods without "personnel labor heroism".

II. Changing the areas of responsibility for seniority levels. The new health and safety management system changes the health and safety vector and instead of procedures and methods to response any manufacturing incidents that took place, instead of performing certain actions to repair consequences of industrial injuries and work-related disorders it is focused on monitoring and forecasting any possible untoward conditions, on implementing preventive measures aimed to minimize the impact of hazardous and harmful manufacturing factors. Methodical content of the professional risks management system consists of some processes for discovering, distinguishing and eliminating hazards and harmful conditions, and for implementation thereof other officials' areas of responsibility are required and other competence level of managers and specialists.

An employer is a key element in such new health and safety management system at companies not only due to the fact that he performs the duties of a chief executive officer but also owing to the fact that at present the Russian law lays the overall responsibility for arranging the works to ensure the necessary labor safety level upon him. The conventional 
health and safety management system specified such duties vaguely failing to adequately personify them, primary work to prevent industrial injuries and work-related disorders was performed by a labor safety engineer and company's respective service, its actions were supervised by an engineer-in-chief.

The management theory uses the connecting vessels rule that indicates that managerial decisions efficiency depends on the extent to what an employee's responsibility level corresponds to the level of his capabilities and powers. (Fig. 3). An employer has utmost powers in a company, he controls financial, material, personnel and other resources, this is why he has opportunities in the context of available powers to deal with most complicated challenges with greater success. Unlike a chief executive officer, labor safety specialist has limited powers, he has no opportunity to give instructions by order to managing staff or to command financial assets. This is why a labor safety engineer may not be liable to the full extent for injuries and work-related disorders level.

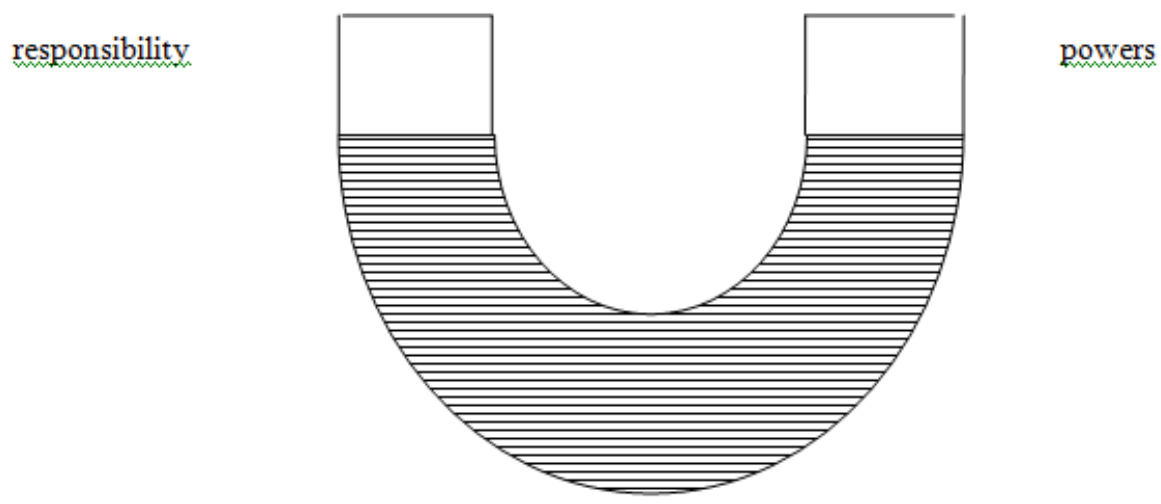

Fig. 3. Management Connecting Vessels.

An employer's primary instrument for obligations performing to prevent industrial injuries and disorders is a well-organized company's health and safety management system (HSMS) that theoretically shall be integrated into the unified company management system [14]. Being personally liable for the general state of the company's labor safety, an employer shall delegate some powers to subordinate management levels, whose managers are responsible for labor conditions at their dependent and manufacturing sections. Thus, a chief executive officer shall arrange the work for health and safety management in a company and secondly shall guarantee its subordinate employees safe labor due to creating correspondent labor environment.

An employer's principal assistant in the course of his challenges implementation is a health and safety specialist. In compliance with its duties nature he is not included to the company's process management system and has no authoritative powers at any manufacturing sector. This is why labor safety specialist having no respective controlling capabilities may not be administratively and legally liable for any incident happening in the area of responsibility of the head of manufacturing sector or an employer. Labor safety specialist actually performs command unit employee's duties: in his capacity of the manager's assistant and authorized consultant he may recommend, inform, arrange and coordinate labor safety work. Such status does not lower a labor safety specialist's authority, just the other way round, it makes more strict requirements to his competence, professional experience, personal qualities [15]. 
Manufacturing sector's principals are responsible for labor safety at such sectors. They assist health and safety division to discover and distinguish hazardous and harmful factors, participate in technical solutions preparing to minimize or eliminate them. When implementing adopted solutions, middle managers become responsible executives, they have enough organizational and material resources therefor and proper authoritative powers at their sectors. When implementing measures a labor safety specialist shall consult and control responsible executives, perform the field supervision duties, participate at all stages of solutions implementing up to the works completion. Any mistakes in technical documentation, improper suggestion, incorrect technical solution shall be a labor safety specialist's responsibility, such measures poor implementation shall be the responsibility of the division's principal.

III. Labor collective role strengthening. To arrange an effective management system it is not enough to change the areas of responsibility for top, middle and low-level managers, reorganization success shall be impossible without broad participation of labor collective members in health and safety measures development, implementation and control. Close social partnership between the managers and labor collective shall encourage suitable environment establishing in order to mobilize both parties to provide safe labor process, to involve into the creative process all the company's employees starting from an employer up to low-level positions holders. Regulatory documents specify that an employer shall provide conditions enabling labor collective representatives to have enough time and capabilities to be fully engaged in the processes of arranging, scheduling and implementing measures regarding labor safety, management actions control and assessment, to be involved into consultations. The emphasis is made that such activity regarding employees involvement is deemed the most important element of health and safety management system in a company. We shall add that it is also the most complicated in implementation, much more labor-intensive than upgrading management divisions activity [16].

An instrument fit for implementing social partnership concepts is creating by a company a Committee (Board) for Health and Safety and its functioning. Health and safety Committee is a consultative body assisting an employer; it may be initiated by him or by his employees. Its members are employer's and labor union organization's representatives on a parity basis. Its Chairman is as a rule an employer, its Vice-Chairman is a labor union organization's representative, its secretary is an employee from employer's health and safety division. The Committee is an employer's health and safety management system (HSMS) component, and a form of employees participation in health and safety management. The Committee for Health and Safety is mentioned in the Labor Code of the Russian Federation, and in June 2014 the Russian Ministry of Labor ratified a new Standard Regulation regarding the Procedure for the Committee Establishment and Operations.

The Committee shall primarily deal with the creational matters, settle general and special questions regarding constructing contemporary health and safety model at companies, and supervising functions shall be put aside. The collective body shall encourage formulating company's unified policy to implement safe manufacturing goals, operations methods and approaches consistency, safe labor similar priorities for the whole manufacturing collective. The principal goal for the Committee for Health and Safety is performing the work regarding formulating the company's goals and objectives in the sphere of safe labor. Labor conditions improving and working place comfort rising shall be the company's goal that shall not be deemed as public authorities outer requirement to manufacturing process, just the other way round, it shall be deemed as intraproductive objective and dealt with taking into consideration:

- statutory and standard requirements to labor safety;

- company's financial and economic and business goals;

- company's social function regarding its own employees. 
The Committee's focused efforts shall enable in due course of time to develop and polish health and safety management system satisfying contemporary requirements, and to form personnel's conscious motivation for safe behavior in the widest sense. Employees reasonable behavior and effective system for professional risks discovering and eliminating is the principal goal of company's managers activity, and the principal instrument for achieving thereof shall be the operations performed by the Committee for Health and Safety.

Positive influence of the Committee's operations is evidenced by the fact that it is capable of transforming the labor safety challenges into a more urgent and preferred performance level, helps to hasten the process of a company's health and safety management system reforming, to raise the health and safety credibility and meaning to provide the company's competitive ability.

Unfortunately, the great majority of Russian companies have failed to see reasonability in such structure arrangement. Even labor union organizations showed little interest in an appropriate opportunity to exercise extra control for employer's activity, to discuss and offer for implementation health and safety measures in the context of officially ratified instance. It seems that companies managers underestimate the capabilities for health and safety management system reorganization, for labor collective and management personnel consolidation, for forming actual social partnership being the result of such Committee's activity.

In their days in German companies such structure played substantial role in industrial injuries preventive measures. The requirement regarding the Committee for Health and Safety establishing and maintenance by an employer was specified in the Health and Safety Act adopted in the mid-1980s and according to some specialists estimations it turned out the most valuable part of the Act. Actually, a specialized area available for discussing and making collective solutions taking into consideration the view of the management, company's Board and that of the labor collective representatives enabled to sufficiently accelerate switching to a new labor safety management system. Taking into consideration the high efficiency of the Committees for Health and Safety in several years the German legislators included to some act a binding provision regarding establishing at major companies similar Committees for Industrial Medicine [16].

IV. Information and propaganda activity. Company's unified policy implementation regarding settling the challenges of safe manufacturing, operations methods and approaches consistency, similar priorities shall be impossible without information and propaganda activity performed by health and safety specialist together with companies management. To focus efforts upon general goals implementing regarding labor safety it is deemed necessary to constantly inform the labor collective and management on the matters of manufacturing safety.

Informative procedures include collective talks, visual propaganda and respective posters, regular speaking at operational and general meetings, arrangement of "A Labor Safety Day", special explanation sheets and reminder cards, training materials, using plantscale radio. Special emphasis is laid upon a special board or stand installation near the entrance to the company helping to inform the personnel about labor safety state at working places. Such activity not only encourages to improve labor conditions, it affects favorably management actions openness and transparency, trust enhancement to principals, has a positive impact upon their authority.

\section{Conclusion}

Health and safety shall start neither at the machine site, no at the working place. To a far greater extent labor safety as well as any other manufacturing aspects are traced back from 
the solutions made by officials having respective philosophy and implementing contemporary occupational safety and health management system. Unfortunately, personnel preparation for contemporary health and safety management system falls substantially behind the actual needs. There are two directions for educational activity: for the long term that is young specialists preparation in the context of higher professional education receiving and for the short term via the advanced training measures of employed specialists among higher and middle managers. Each direction has its advantages and drawbacks and in whole they complement each other and provide educational process harmony. At the same time the second direction is deemed more effective it enables to urgently put to manufacturing process's notice the essence and content of contemporary health and safety model, assists conscious and reasoned decision for the challenges regarding health and safety management system reforming.

\section{References}

1. A.G. Fedorets, Occupational Safety Management and Risks Estimation (ANO IBT, Moscow, 2012)

2. R.A. Litvinov, Health and Safety and Accidents Prevention in Construction Industry 4, 12-18 (2013)

3. E.B. Sugak, Life Safety 7, 3-7 (2015)

4. Health and Safety, 207/B (2006)

5. S.S. Kozitskiy, Health and Safety and Accidents Prevention in Construction Industry 6, 55 (2012)

6. Russian Standard GOST 12.0.230-2007

7. Russian Standard GOST P 54934-2012

8. Occupational health and safety management systems (OHSAS 18001, 2007)

9. Guidelines on occupational safety and health management systems (International Labor Office, Geneva, 2001).

10. G.I. Tikhonova, A.N. Churanova, T.Y. Gorchakova, Occupational Medicine and Industrial Ecology 3, 9-14 (2012)

11. T.A. Golikova, Health and Safety and Accidents Prevention in Construction Industry 1, 7-11 (2012)

12. E.B. Sugak, MSCU, 185-186 (2013)

13. H.W. Heinrich, Industrial accident prevention; a scientific approach (McGraw-Hill, New-York, 1959)

14. A.V. Moskvichev, N.I. Simonova, S.V. Vikhrov, V.V. Ivanov, Health and Safety and Accidents Prevention in Construction Industry 5, 56-60 (2016)

15. E.B. Sugak, Man and Labour 10, 48-51 (2013)

16. E.B. Sugak, Life Safety 6, 6-10 (2016) 